\title{
Ensuring economic security of the enterprise in anti-crisis conditions
}

\author{
Anna Zigunova ${ }^{1 *}$, Nikolay Shevkunov ${ }^{1}$, Irina Logvinova $^{1}$, Iliya Kislov $^{1}$, and Vitaliy \\ Shevchenko ${ }^{1}$ \\ ${ }^{1}$ Rostov State Transport University, sq. Rostovskogo Strelkovogo Polka Narodnogo Opolcheniya, 2, \\ Rostov-on-Don, 344038, Russia
}

\begin{abstract}
The article presents the author's approach to the essence of the process of ensuring economic security of an economic entity in the conditions of anti-crisis management. The authors analyze the main directions in the field of economic security, including the development and implementation of a system of economic, legal and organizational measures aimed at minimizing the level of influence on the formation of financial, material, information and human resources of external and internal threats in anti-crisis conditions. Anti-crisis management in such circumstances is the main tool for ensuring economic security and focuses on minimizing or eliminating risks and threats through the use of current methods and techniques, as well as modern management capabilities that allow developing priority activities of socially and economically promising economic entities.
\end{abstract}

\section{Introduction}

The transformation of the Russian economy and the transition to modern forms of public administration, as well as serious transformations of the social sphere, generate all sorts of risks and threats and actualize the problems of anti-crisis management of economic security of economic entities. The need for security is the main one for economic entities, as it is considered as the basic characteristics of the formation, functioning and development of any economic and other systems. If this need is not realized, then there are problems such as a lack of resource base, reduced efficiency and aggravation of socio-economic contradictions between all economic entities. At the same time, it is necessary to remember that the possibility, and sometimes the need for a crisis in the conditions of cyclical economic processes, allows you to identify and implement growth reserves and update the development strategy of enterprises that are on the way to bankruptcy due to unwillingness or inability to adapt to changing market conditions. Anti-crisis management in such conditions, focused on minimizing or eliminating risks and threats through the use of current tools and capabilities of modern management, allows you to maintain the activities of socially and economically promising economic entities.

\footnotetext{
*Corresponding author:: ann-rgu@ yandex.ru
} 
The main management tools in anti-crisis conditions, especially in the context of a financial crisis, should be aimed at restoring the financial balance of the enterprise and minimizing the scale of the decline in its market value [1]. With a systemic approach to crisis management provides for the formation of a system of integrated activities, including all stage management from pre-diagnosis crisis methods to eliminate or overcome them.

Some Russian scientists define crisis management as a managed process of preventing or overcoming a crisis that corresponds to the organization's goals and objective trends in its development. The peculiarity of such management is that management decisions are often made in conditions of uncertainty, reduced manageability of the business entity and conflict of interests of various professional groups due to crisis conditions.

The realities of the current economic situation require economic entities to form, implement and implement the principles and provisions of anti-crisis management that would avoid the crisis or, if it occurs, withdraw unprofitable enterprises from it.

Modern conditions of economic development of economic entities define most of them as unprofitable, experiencing a production downturn and being in a critical state or on the verge of bankruptcy. The main reasons for the crisis development of the enterprise are the inertia of functioning production structures, technical and technological backwardness of individual production systems and significant physical deterioration of fixed assets in certain industries. In addition, destructive factors include the lack of priorities of the state scientific and technical policy, which does not allow the real sector of the economy to restructure production capacity. These factors will have a negative impact on the regional and social economy and social stability in General, as well as on the potential of each individual economic entity, since any production entity, being a structural element of the economy, bears a certain social burden and responsibility.

\section{Methods}

The development and implementation of a system of economic, legal and organizational measures aimed at minimizing the level of influence on the formation of financial, material, information and human resources of external and internal threats should be a priority in the field of economic security.

Economic security acts as the internal state of an economic entity that allows it to develop and at the same time minimize the impact of external negative factors. Effective economic security is determined by the effectiveness of the use of such types of resources of an economic entity as (Fig.1). These resources are actively involved in the process of neutralizing threats to economic security and play a leading role in the development of measures to improve the efficiency of the main activities of the economic entity, so the structure of functional components of economic security along with these types of resources should include financial and economic, marketing, technical and technological, and personnel components. Economic-financial component of economic security entity describes its financial soundness and guarantees its solvency, as it is failing to meet their obligations can have on a business entity such consequences as bankruptcy and liquidation. Accordingly, the assessment of financial stability and solvency should become the first and main direction in the system of ensuring economic security of an economic entity. In addition, to obtain full and reliable information on financial and economic condition of the entity with the purpose of determination of level of economic safety it is necessary to estimate factors of profitability, which is defined as the utilization of various resources. At the same time, the development of an economic entity is a mandatory and necessary requirement of its economic security, since only maintaining the achieved level of activity does not guarantee the preservation of competitive positions in the market in the conditions of dynamically developing economic relations. 


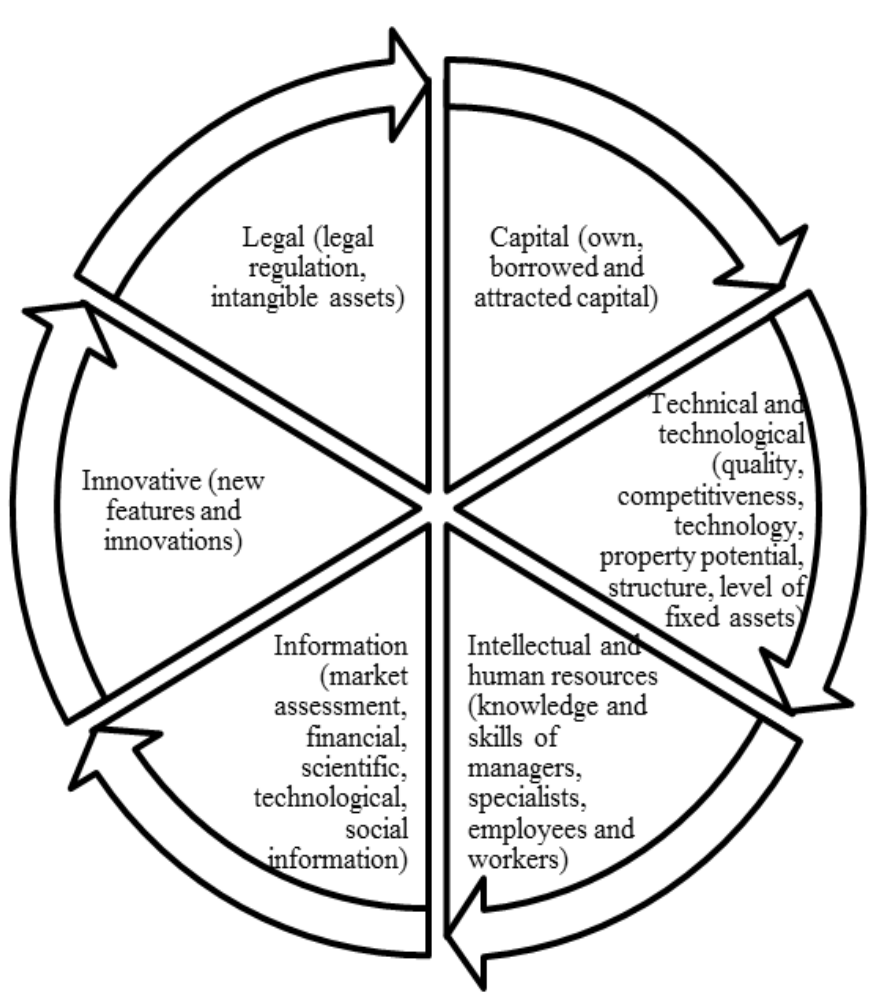

Fig, 1. Types of resources used to ensure economic security.

Economic-financial component of economic security entity describes its financial soundness and guarantees its solvency, as it is failing to meet their obligations can have on a business entity such consequences as bankruptcy and liquidation. Accordingly, the assessment of financial stability and solvency should become the first and main direction in the system of ensuring economic security of an economic entity. In addition, to obtain full and reliable information on financial and economic condition of the entity with the purpose of determination of level of economic safety it is necessary to estimate factors of profitability, which is defined as the utilization of various resources. At the same time, the development of an economic entity is a mandatory and necessary requirement of its economic security, since only maintaining the achieved level of activity does not guarantee the preservation of competitive positions in the market in the conditions of dynamically developing economic relations. In such conditions, the importance and influence of the marketing component in the system of ensuring economic security, which determines the role and stable position of an economic entity in the market, increases. Competitive products sold on the market allow the business entity to reduce production costs and costs associated with the sale of products on the market, but it is also necessary to observe that products with a higher level of quality may be less competitive if their cost is unreasonably high. Criteria-based assessment of economic security of an economic entity should be based on the assessment of such elements as:

- resource potential and development opportunities of an economic entity;

- resource efficiency and its compliance with industry (global) indicators and the level of minimal internal and external threats;

- competitiveness of products; 
- market development;

- ability to resist external threats;

- social stability.

The main indicators of possible future deterioration of the financial situation can be:

- insufficient diversification of production;

- loss of business connections and contacts, as well as complication of relationships with key contractors;

- lack of financial and other resources for technical and technological renewal of production and re-profiling of personnel;

- inefficient long-term contracts and agreements;

- incorrect choice of innovative investment projects aimed at increasing financial results;

- saturation of the market segment with stronger competitors.

Indicators of financial difficulties that have already occurred are often:

- loss of long-term contracts and drastic changes in the order portfolio;

- forced production stops that lead to a failure of its rhythm;

- change in the price of capital;

- increase in production of defective products and return of non-conforming products;

- financing long-term expensive projects with short-term borrowings;

- lack of working capital;

- increase in the share of inefficiently used or unused fixed assets,

- unjustified increase in production stocks;

- ineffective policy of re-investments [2].

The functioning of an economic entity in conditions when the values of indicators go beyond the normalized values will be considered as a crisis. Normalization of the financial and economic situation at the enterprise will involve the use of special anti-crisis management methods to get out of the current situation, implemented within the framework of certain areas [3]. The implementation of the company's anti-crisis management policy provides for the following main directions (Fig.2):

Monitoring the financial condition of an economic entity in order to detect early signs of a crisis in its functioning and development

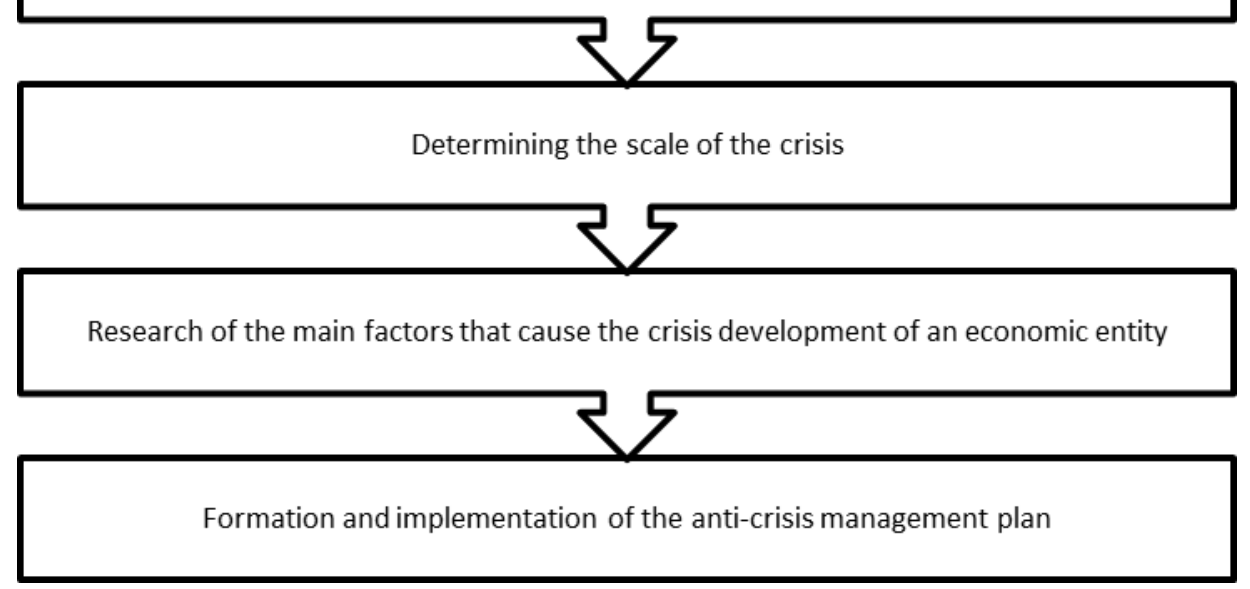

Fig. 2. Main directions implementation of the anti-crisis management policy of an economic entity.

These directions determine that the essence of anti-crisis management is to develop and implement the most rational and cost-effective way to bring an economic entity out of the crisis, based on the analysis of its symptoms, developing measures to reduce its negative 
consequences and using its factors and consequences as a new stage for future development.

Factor analysis is the primary operation of crisis management, providing a basis for assessing the crisis situation and forming a strategy of behavior that allows implementing economic methods of crisis management. The analysis of external factors is aimed at finding out what an economic entity can expect when using rational management methods and what complications may arise in its activities if it does not Orient itself in the market situation and fails to respond adequately to its sudden changes. The analysis of internal factors defines the opportunities and distinctive advantages that an economic entity possesses in the competitive market struggle, as well as its weaknesses that cause an unstable and crisis situation.

Once the internal and external factors of the crisis state of the enterprise are identified, the stage of analysis and comprehensive review of the current market situation in which the organization operates begins.

The analysis of the above factors makes it clear that management decisions made taking into account the assessment of the impact of only external or only internal factors will not be sufficient and systemic. Based methods of crisis management can be generated based on the data analysis revealed a full list of the defining activities of the entity factors and the most probable trends of their development and changes with the establishment of major forces and mechanisms that provide them significant influence.

The initial basis for such analysis in market conditions is SWOT analysis, which allows you to qualitatively analyze, structure and evaluate the strengths and weaknesses of the business entity, as well as potential external threats and favorable market opportunities. If we consider these categories from the point of view of factor analysis, internal factors are strengths and Weaknesses, external factors are opportunities and threats.

SWOT analysis can be performed in the following areas::

- the subject as a whole;

- individual business areas;

- the markets in which the entity operates;

- specific product-market combinations;

- analysis perspective (current, short-term, long-term).

Taking into account the SWOT analysis data, it is possible to build an anti-crisis program in accordance with clearly formulated main goals that provide the economic entity with the required level of economic security. Such goals will differ for each business entity, as they depend on the financial and economic condition of the enterprise, its position on the market, competitiveness, investment attractiveness, and other things, but in modern conditions, we can distinguish a number of goals that are equally important for any business entity, implemented in anti-crisis programs. These goals include:

- preventing a decrease in production volumes

- maintaining the level of overall profitability;

- increasing production and sales volumes;

- reducing the overall cost level;

- increasing the level of profitability and profitability of activities;

- optimizing the structure and increasing the degree of return on assets;

- optimization of the tax burden;

- increasing the level of competitiveness;

- implementation of the mission through the achievement of social goals;

- maintaining, incrementing or modifying the number of jobs, wages, and social stability;

- formation of a sufficient level of social security of the team. 
Ensuring the economic security of an economic entity in anti-crisis conditions should be based on the developed strategic plan, which defines General and functional recommendations for the implementation of planned installations that contain certain quantitative characteristics and are issued in special annexes to the strategic plan.

The process of implementing strategic plans of an economic entity involves the need to conduct an operational assessment of the level of economic security and current tactical planning as a logical continuation of the strategy implementation process. The analysis of ensuring the necessary level of economic security should take into account the results of evaluating the effectiveness of the applied measures aimed at preventing damage and determining the functional and aggregate criteria for economic security of the economic entity. The current planning of the process of ensuring the economic security of the subject is carried out taking into account the formation and selection of several alternative scenarios of situational development and determining the threshold values of the aggregate criterion of economic security for each of them. Implementation of this process makes it possible to develop operational recommendations for current planning of activities that set both qualitative and quantitative guidelines for the current activity of the economic entity.

Defining requirements for strategic planning in anti-crisis conditions are:

- feasibility study of resource management efficiency;

- ensuring an effective threshold for economic security criteria and parameters;

- formation of a system of measures to preserve the formed market potential;

- identification of additional sources of resource support;

- implementation of modern methods of competition in various market segments.

At the same time, in order to implement an effective process of ensuring economic security, it is necessary that when formulating goals and defining objects of the strategy for ensuring economic security:

- the characteristics of various threats and risks to the economic security of the enterprise were taken into account;

- identified and monitored factors that characterize the stability of the socio-economic situation of the economic entity in the short and medium term;

- threshold values of criteria and parameters of economic security were formed;

- mechanisms for taking into account the factors of economic policy development that affect the state of economic security were taken into account;

- the directions of activity of the economic entity for the implementation of the strategy were defined.

\section{Results}

The quality of products, works and services sold on the market, their competitiveness and, as a result, the costs of an economic entity will depend crucially on the technical and technological level of production, which indicates the importance of the technical and technological component of economic security. This factor takes into account the state of fixed assets and the effectiveness of working technologies used, taking into account the innovative component of development necessary for the survival of an economic entity in the long term.

Under the current conditions, the main direction of anti-crisis management is the development of the internal economic mechanism as a stage of forming internal standards that ensure the safety and rational use of all types of available resources [4]. In addition, a positive impact on the formation of anti-crisis measures will have the formation of financial responsibility centers as an element of the intra-economic structure, which will allow by delegating maximum powers to divisions to rebuild the management and control systems of the economic entity, thereby increasing the profitability of each specific division. This 
approach to the formation and implementation of anti-crisis policy will allow the most complete compliance with the requirements of resource conservation.

In General, the implementation of the set of proposed anti-crisis measures will increase the level of economic security of an economic entity in the changing market environment and create an effective model of its functioning.

Thus, the process of ensuring economic security in anti-crisis conditions should consist of the following sequential procedures (Fig.3):

Selection and justification of the system of indicators - indicators of economic security

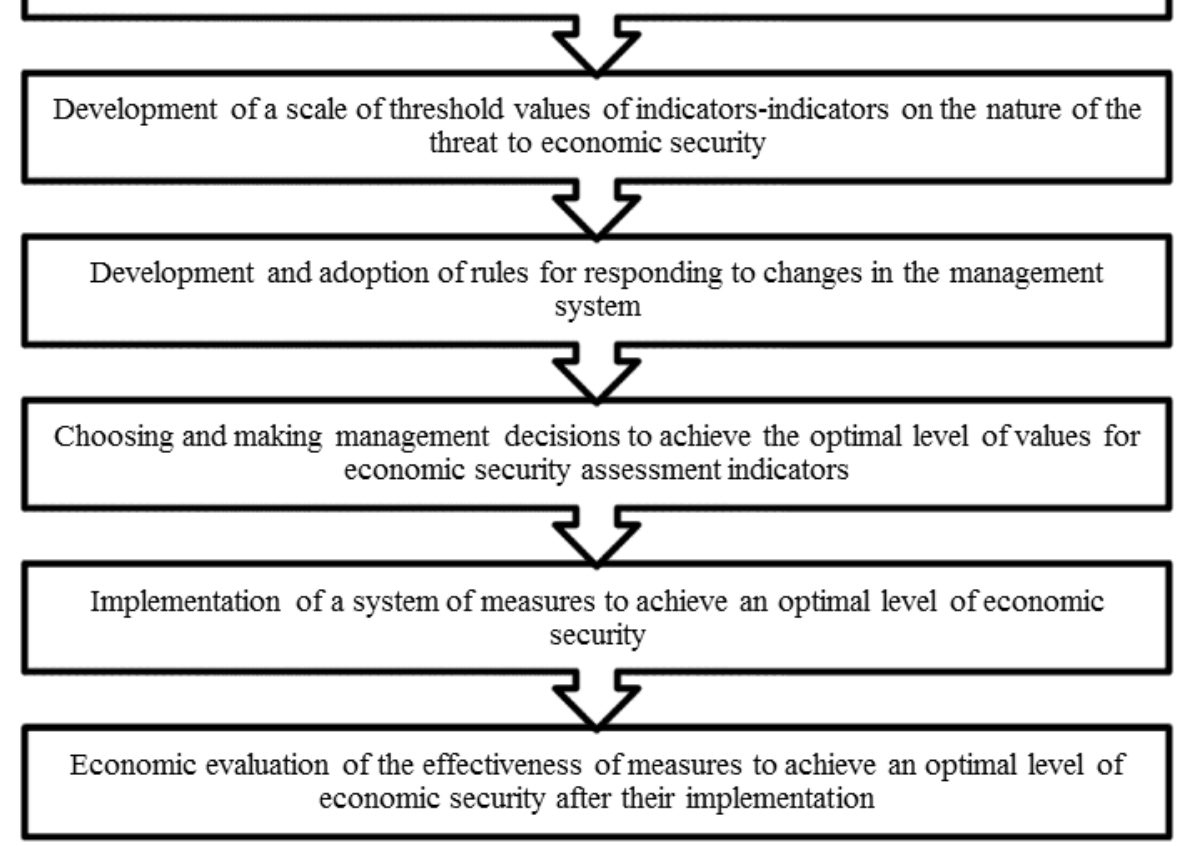

Fig. 3. The process model of management of economic safety of the enterprise.

When forming a system of indicators-indicators of economic security, consistent with the basic goals of anti-crisis policy and other development programs of an economic entity, it is necessary to focus primarily on indicators that characterize the financial and economic situation and performance. Such a system of indicators can be supplemented with criteria that detail the economic state of an economic entity in the context of individual processes that affect economic security. The multi-level nature of the used system of economic security indicators will allow us to track in more detail the ongoing processes and timely diagnose the emerging problem segments.

When developing a scale of threshold values of indicators, it is necessary to take into account the degree of risk of reducing the level of economic security, taking into account the specifics of the business entity's activity, its market environment and dependence on external factors. The presence of such a scale of threshold values will allow you to quickly identify deviations in work or in the financial and economic state and respond to them by taking the necessary actions that neutralize the negative impact.

The regulation of actions for the management system's response to negative changes in indicator values in various situations may include both standard and specific characteristics and actions for each specific indicator, including taking into account the opinion of competent experts. 
Selection and management decisions aimed at achieving the optimal level of economic security indicators should be based on valid rules of action, taking into account characteristics specific production situation because of the influence of internal or external factors.

The implementation of the system of measures to achieve the optimal level of economic security indicators should be accompanied by coordinated actions of the relevant structural units that carry out their activities within the framework of the anti-crisis program.

Economic evaluation of the effectiveness of measures to achieve an optimal level of economic security will allow you to evaluate not only the efficiency of the enterprise, but also the quality of management decisions in General.

Thus, the proposed model of formalization of the process of ensuring economic security in anti-crisis conditions will allow an economic entity to prevent or more quickly solve emerging problems in ensuring economic stability and market stability and be more stable in relation to changing external conditions of activity.

Control and monitoring of the efficiency of functioning in a crisis will allow an economic entity to form a system of criteria for assessing the level of its economic security. The development and adoption of strategic management decisions in a crisis should take into account the monitoring data of key economic indicators that reflect the current state of the business entity and trends in various areas of activity, as well as their compliance with threshold values.

Also, improving the mechanism of state regulation of economic growth through the formation and implementation of conceptual programs and documents for interregional and territorial planning, as well as creating a comprehensive risk control system, will help to achieve the optimal level of economic security.

In General, measures to ensure the economic security of an economic entity can be divided into four groups (Fig. 4):

Humanitarian measures (basic elements of security relations, consideration of the interests of interacting parties)

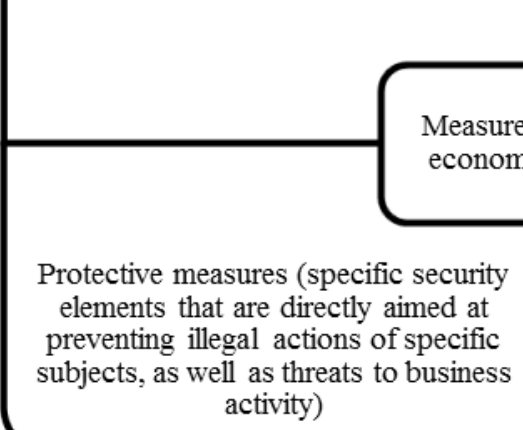

Fig. 4. Measures to ensure economic security in anti-crisis conditions.

The list of measures listed above does not pay enough attention to humanitarian measures, which is unjustified. Ensuring the economic security of any business entity begins with the process of strategic goal-setting and identifying the needs and interests of employees, that is, taking into account the factors of the socio-psychological group related to humanitarian measures.

Problems of ensuring economic security should be solved taking into account scientifically based management and forecasting, economic calculations, analysis and 
justification, as well as developing solutions based on the concept and strategy of economic security of an economic entity. At the same time, the most important stage of ensuring the economic security of an economic entity is strategic planning and forecasting of its economic security, which determine the qualitative parameters of the use of corporate resources in relation to the organizational and functional structure of the economic entity and structural divisions, as well as certain quantitative guidelines for ensuring functional components.

Thus, the process of financial-economic activity of the subject generates sufficient for analysis of level of economic security the amount of information on the basis of which the rating of criteria of economic safety, analysis of deviations from planned values and their causes. The results of such analysis and evaluation will allow us to form recommendations for adjusting the corporate resources necessary for effective operation and improving the systems of strategic, current and operational planning and management of financial and economic activities of an economic entity.

\section{Discussion}

The essence of the category "economic security" can be described as the financial and economic state of an economic entity, in which the obligations assumed are repaid in a timely manner, social functions are implemented and the economic potential is formed, allowing it to carry out its main activities even in unfavorable conditions of development and market conditions.

Current economic growth conditions require identifying possible risks and threats at earlier stages of their occurrence, as well as developing and implementing preventive anticrisis management measures aimed at ensuring economic security. These provisions are put forward to the task of internal self-assessment and forecasting of financial and economic condition, taking into account the realization of their inherent production steps for the formation of the system of protective measures and, consequently, economic security of economic entities, creation of a system of threshold values of indicator monitoring security and, on this basis, the development of measures of counteraction to external and internal threats.

However, it should be noted that the problems of ensuring economic security arise not only in times of crisis, but also when operating in a stable financial and economic environment, so the set of tasks to be solved in this case will differ significantly. In particular, when operating in a sustainable manner, the company focuses on maintaining a normal work rhythm, preventing damage or losses, preventing unauthorized access to information and databases, and countering unfair competition and the shadow economy. During a crisis, a significant threat to an economic entity is the weakening or destruction of its production, technological, scientific, technical, and human resources potential and the blocking of its development opportunities.

The main goal of crisis management in ensuring the economic security of the entity becomes an analysis of the factors of origin and development of the crisis situation, and developing and implementing a comprehensive economic mechanism of crisis management, which consists in monitoring the external and internal environment of the subject for early detection of signs of the origin of the crisis situation, operational analysis and evaluation of its financial condition and the likelihood of bankruptcy, as well as the formation and implementation of measures aimed at overcoming the crisis.

This area of economic research has proved its importance in times of crisis, but it should be noted that modern methods of crisis management require immediate response and constant adaptation to the changing market conditions. The process of improving and 
developing an economic mechanism for crisis management can be implemented at the following main stages:

- identification of the main external and internal factors and signs of crisis phenomena in the economic activity of an economic entity;

- assessment of identified factors;

- development and determination of the position of economic methods of anti-crisis management in the strategy of an economic entity;

- implementation of these anti-crisis management methods and monitoring their implementation.

\section{References}

1. S.V. Zenchenko, M.L. Vartanova, Economics, entrepreneurship and law, 9, No. 4, 257 270 (2019) doi: 10.18334/epp.9.4.41462

2. G.A. Alexandrov, I.V. Vyakina, G.G. Skvortsova, Economic relations, 9, No. 3, 22692284 (2019) doi: 10.18334/eo.9.3.40915

3. S.I. Morozov, O.V. Asmus, O.V. Zhigalova, Economic relations, 9, No. 3, 1683-1696 (2019) doi: 10.18334/eo.9.3.41060

4. I.M. Glotin, Journal of Creative economy, 13, No. 11, 2227-2236 (2019) doi: $\underline{10.18334 / \text { ce. } 13.11 .41292}$ 